\title{
Application of Adaptive Neuro-Fuzzy Inference System for Prediction of Mean Thickness in Backward Metal Flow Forming Process
}

\author{
Prabas Banerjee ${ }^{1, *}$, Arnab Karmakar ${ }^{1}$, Nirmal Hui ${ }^{1}$ \\ Department of Mechanical Engineering, National Institute of Technology, Durgapur-713209.
}

\begin{abstract}
In the backward metal flow forming process, the mean thickness of flow formed tubes is crucial in determining the quality. Consequently, predicting the mean thickness in incremental forming and correlating these values with the forming parameters can be useful to control this vital target. Accordingly, four different techniques of adaptive neuro-fuzzy inference system (ANFIS) is used to predict the mean thickness of parts produced by the backward metal flow forming process. The objective is to determine the best membership function of the different approaches used in ANFIS. Also, the efficiency of the developed predictive models is compared statistically to determine the best technique.
\end{abstract}

Keywords: ANFIS, Mean thickness, backward flow forming, predictive model.

\section{Introduction}

The metal flow forming process finds its application in the aerospace, defence and automobile industries [1]. In aerospace, it is widely used in the production of drive shafts for helicopters and airplanes [2]. The shafts manufactured by the flow forming process eliminates the distortion in wall thickness, thus reducing the cost for balancing. Tailor rotor shafts used in helicopters are often made up of titanium, stainless steel, or aluminium [3]. The shafts are required to be straight, and very high precision is necessary for the thickness of the flow formed tubes. This precision could be achieved easily by the metal flow forming process. The metal flow forming process finds its application in the automobile industry. Flow formed components with high precision in wall thickness are used as disc carriers. Such members are exposed to high strain [4]. The cold flow formed components provide high strength components. Thin walled high strength are some of the prerequisites for rocket motors and other light-weight construction parts such warheads. Thus, maintaining high precision for the thickness of flow formed tubes is paramount. One of the critical requirements in the metal flow forming process is the precision of the flow-formed tubes [5] [6] [7].

Experimental studies [8] [9] were conducted to determining essential parameters that influence the thickness of flow formed. Davidson et al. [10] used experimental analysis to study the effect of input parameters on percentage elongation. For finding the relationship between the forming parameters, Taguchi analysis was performed. The axial feed of the roller, the roller's speed, and the percentage reduction were considered at different levels. It was suggested that the depth of cut was the most critical parameter. In metal spinning, multi-pass of the roller is required to prevent excessive thinning of spun parts. Wang and Long [11] used Taguchi analysis to study the effect of forming parameters on spun tubes' mean thickness. The type of material used and the feed speed ratio of the roller are the critical factors. In soft materials like 
aluminium, wrinkling occurs, while in materials like steel, wrinkling phenomena are not observed. At a high feed speed ratio, the desired thickness is achieved, but cracks can develop on the spun tubes' surface. Banerjee et al. [12] developed a predictive model for determination of mean thickness with known input parameters. The ANN model was compared with statistical based regression model. The superior capability of ANN enabled better prediction than regression model. Previously ANFIS approach has applied to various metal forming processes. Bikramjit et al. [13] used ANFIS to model the dimensional accuracy like inside diameter, spring-back, and flow-formed tubes' ovality. The ANFIS model outperformed the regression model in the prediction of the inside diameter, springback and ovality. Bikramjit et al. [14] compared the forward and the reverse model based neural networks. The networks were optimized using three techniques such as back propagation, LBFGS and genetic algorithm. Among the three techniques, GANN emerged as the best technique in the prediction of the final dimension of flow formed tubes.

ANFIS is a combination of two soft computing techniques, such as artificial neural network (ANN) and fuzzy logic theory. The ANFIS is trained just like an artificial neural network and the solutions are mapped through a fuzzy inference system [15] [16]. In this research, ANFIS is used to model the input parameters for the determination of the output of the backward flow forming process. Seven different membership functions are considered in the four different approaches. Measures of different error are performed. Statistical comparison is made for identifying the approach that would efficiently predict the final dimension mean thickness for a set of input conditions.

\section{Problem formulation and Experimental methodology}

The flow forming process is primarily divided into two types, viz. forward metal flow forming and backward metal flow forming [17]. In backward metal flow forming the roller traverse in the opposite direction to the elongation of the tubes. In the forward metal flow forming process, the rollers move in the same direction as the metal elongation [18]. In this research, a backward metal flow forming process is used to produce long cylindrical tubes. The radial compression of the rollers reduces the thickness of the tube. The deformed material elongates along the axial direction. The elongating material is surrounded by the preform material. The unconstrained deformation causes variation in the thickness of flow formed tubes. Variation in thickness in flow formed products is highly undesirable. There is continuous engagement and disengagement of contact between the roller and the preform material. During the contact of the roller with the preform compressive forces are generated. This forces deforms the material of the preform. While, during no contact the forces of the roller is released temporarily which causes springback of soft ductile materials. This phenomenon often leads to uneven thickness along the length of the preform. Thus, prediction of mean thickness is of utmost importance for better control of the final dimensions of the flow formed tubes. There is no analytical relationship between the mean thickness of flow formed tubes and the input parameters of the flow forming process. This research explores the possibility of developing a predictive model based on soft computing technique. Through this research a mapping between the input and the output parameters would be established and prediction of the response would be made.

The experiments are done based on the full factorial design of experiments methodology [19]. The input and the output parameters are shown in Fig.2. As stated the backward flow forming process is a near net shape manufacturing process that produces high precision long cylindrical tubes. The forming operation is done by Computerised Numerical Control machine (CNC). Figure 3 shows the CNC machine used in this research work. The workpiece prior to the forming process is termed as the preform. The initial dimension of the preform is shown in the Fig. 4(a) and Fig. 4(b) shows the photograph of preform and flow formed tubes. The long cylindrical tube shown in Fig. $4(b)$ is the flow formed tube.

The input and the output parameters were selected based on available literature [20]. Three input factors, such as feed speed ratio [21], infeed [22], and axial stagger [23], are chosen. For each input parameter 4 levels were selected. Most of the literature related to metal flow forming has considered these parameters in their research. Thus, three input parameters with four levels are designed based on the full factorial design of experiments. 
Therefore, 64 number of experiments along with one replication is done. The experiments are carried on a three-axis CNC flow-forming machine. The feed speed ratio is defined as the roller's axial velocity to the rotational velocity of the mandrel. Infeed is the percentage reduction required during one flow forming operation. For multiple rollers, the infeed is equally divided among them. Axial stagger is the distance between the first and the final roller. Mean thickness is considered as the output parameter in this process. Mean thickness is the average thickness of the tube after the forming operation. Uneven thickness of the tube leads to several defects such as wavy surface, crack formation, and enlargement of inner diameter [24].

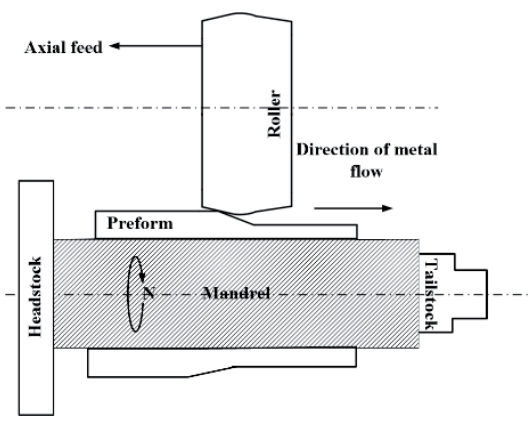

Figure 1: Schematic diagram of backward metal flow forming process

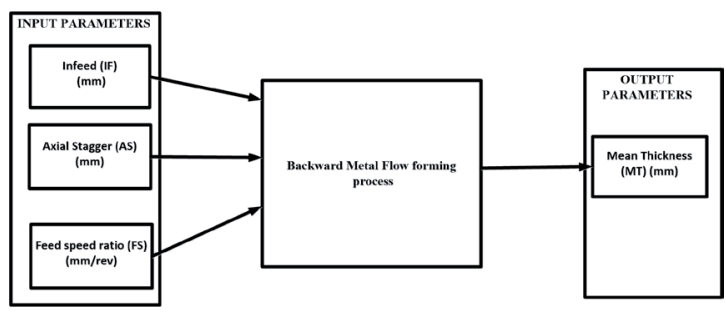

Figure 2: Input and output parameters of a backward flow forming process

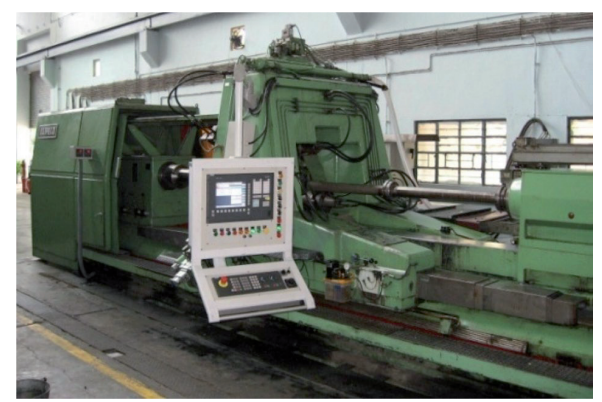

Figure 3: Three-axis CNC flow forming machine (Make: Leifield, Germany)[13]

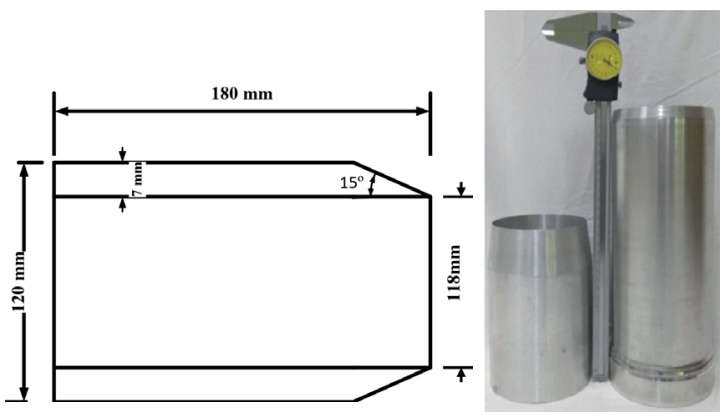

Fig. 4: (a) Schematic representation of preform (b) Photograph of preform and flow formed tubes

\section{Methodology}

Figure 5 shows the schematic representation of the ANFIS [25] model used in this research. It consists of five layers. ANFIS is a combination of two soft computing techniques (fuzzy logic and neural network. Each input is considered to be attached with membership functions. The fuzzification of the real values are done by the membership functions. The fuzzified inputs are tuned by neural networks. The fuzzy rules are framed using the subtractive clustering technique or the grid partitioning method. In grid partition, the fuzzy rule space is uniformly partitioned. One specific area is designated for one rule only. Thus the storage space exponentially increases with increase in the number of input variables. In subtractive clustering the space is divided as clusters. Each cluster centre denotes a specific rule.

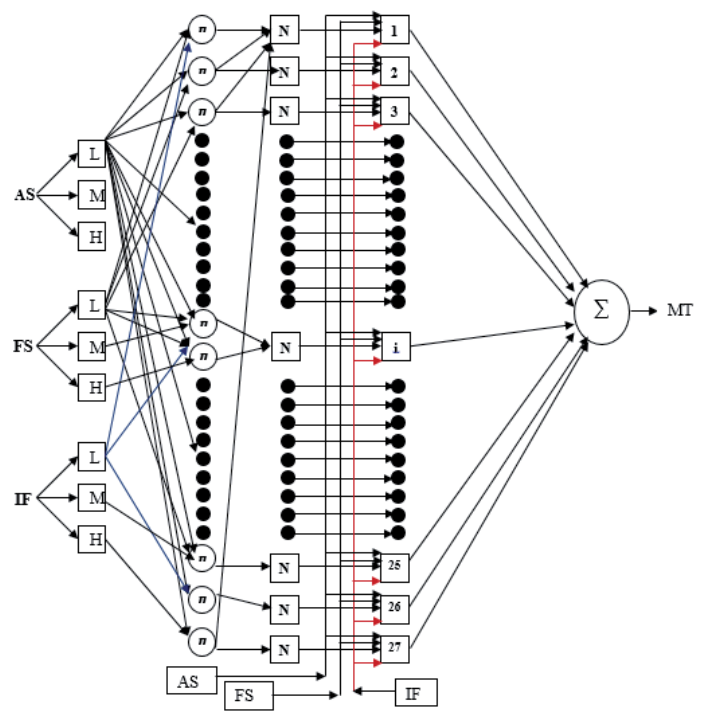

Figure 5: Schematic representation of an ANFIS structure 
Based on these two types and optimization techniques the ANFIS could be divided into four different approaches:

- Approach I: ANFIS is generated using grid partition and optimized through back propagation

- Approach II: ANFIS is generated using grid partition and optimized through hybrid method

- Approach III: ANFIS is generated using subtractive clustering and optimized through back-propagation

- Approach IV: ANFIS is generated using subtractive clustering and optimized through the hybrid method

In all the above approaches, seven different types of membership functions were used, namely: triangular-shaped (trimf), generalized bell-shaped (gbellmf), the difference between two sigmoidal functions (dsigmf), gaussian curve (gaussmf), $\pi$ shaped (pimf), a product of two sigmoidal (psigmf), trapezoidal-shaped (trapmf).

\section{Results and Discussion}

In this research, four types of networks are used for seven different types of membership functions. The training for all the networks is achieved using 128 sets of data and other network parameters. The parameters are varied for finding out the optimized network. For grid partition and subtractive clustering using back propagation,1500 epochs are used, while using hybrid network 200 epochs are used. The parameters are varied till no significant change in RMSE is observed for the training data set. Based on the trained network, the values of the mean thickness are predicted. Here four different types of network models are used, and their prediction of the test data is evaluated. The error performance of the four different approaches is evaluated for eight test data. The error performance measures reported in Table 1, Table 3, Table 5 and Table 7 are defined in Eq. (1-4).

$$
\begin{aligned}
& \text { Mean Square Error (MSE) }=\frac{1}{N} \sum_{t=1}^{N}\left(x(t)-x_{d}(t)\right)^{2} \\
& \text { Half Mean Square Error }=\frac{1}{2 N} \sum_{t=1}^{N}\left(x(t)-x_{d}(t)\right)^{2} \\
& \text { Root Mean Square Error (RMSE) }=\sqrt{M S E} \\
& \text { Absolute Relative Bias (ARB) }=\frac{1}{N} \sum_{t=1}^{N}\left(\frac{x(t)-x_{d}(t)}{x_{d}(t)}\right)
\end{aligned}
$$

Different measures of error performance of approach I are shown in Table 1. 7 types of membership functions related to approach I have been used. For approach I gauss type of membership function gives the minimum error value for different performance measures. ARB's value is least, suggesting that the gauss type of membership function should be used to develop the predictive model. Table 2 shows the slope's values of the best fit line between the experimental value and the predicted value. The fitted line is expressed in the format of $y=m x$ where $m$ represents the slope of the line and $x, y$ represents the target and predicted values respectively. For the ideal scenario the $m$ value should be near to unity and the angle of the line should be at $45^{\circ}$. The angle of the fitted line is given in brackets. It is observed that most of the membership function yields an ideal line having an angle closer to the $45^{\circ}$. Thus, the slope of the best fitted line is not the best technique to judge the efficiency of the membership functions for each technique. Hence, a correlation coefficient is determined for evaluating the closeness of the predicted with the target values. The correlation coefficient between the experimental value and the predicted values are also shown in Table 2 using approach I. The correlation obtained using the gauss type of membership function is 0.8645 , which suggests good agreement between the predicted value and the experimental value. Thus the inference drawn from Table 1 is counter supported by the values of Table 2 . The curvilinear membership functions outperform the linear membership functions such as 'trap' and 'tri' membership functions. Measures of error performance all the curvilinear membership functions are good but 'gauss' gives the least error. The Gaussian curve builtin MF due to its smoothness and concise notation is a popular method for specifying fuzzy sets. The curves have the advantage of being smooth and non-zero at all points.

Table 3 shows the performance of different measures of error using approach 2 of the developed model using ANFIS technique. The 'gbell' membership function has a minimum error value for MSE, HMSE, RMSE, and ARB. Approach II employs both gradient descent and least square technique for optimization of weights in the network structure. Thus the optimization technique is better than that used in approach I. The back propagation has 
Table 1: Approach I

\begin{tabular}{|l|l|l|l|l|l|l|l|}
\hline \multirow{2}{*}{$\begin{array}{l}\text { Type of } \\
\text { error }\end{array}$} & \multicolumn{6}{|l|}{ Type of membership functions } \\
\cline { 2 - 8 } & TRI & GBELL & DSIG & GAUSS & PI & PSIG & TRAP \\
\hline MSE & 4.762 & 0.465 & 0.2042 & $\mathbf{0 . 1 3 7 1}$ & 0.1780 & 0.172 & 0.2369 \\
\hline HMSE & 2.381 & 0.232 & 0.1021 & $\mathbf{0 . 0 6 8 5}$ & 0.089 & 0.086 & 0.1184 \\
\hline RMSE & 2.182 & 0.682 & 0.4519 & $\mathbf{0 . 3 7 0 3}$ & 0.4219 & 0.4147 & 0.4867 \\
\hline ARB & 0.319 & 0.114 & 0.0995 & $\mathbf{0 . 0 8 3 8}$ & 0.0912 & 0.0941 & 0.1162 \\
\hline
\end{tabular}

Table 2: $\mathrm{m}$ and $\mathrm{r}$ values using approach I

\begin{tabular}{|c|c|c|c|c|c|c|c|}
\hline \multirow{2}{*}{$\begin{array}{l}\text { Slope and } \\
\text { correlation } \\
\text { coefficient }\end{array}$} & \multicolumn{7}{|c|}{ Type of membership functions } \\
\hline & TRI & GBELL & DSIG & GAUSS & PI & PSIG & TRAP \\
\hline$m$ & $\begin{array}{l}0.6797 \\
\left(34.2^{\circ}\right) \\
\end{array}$ & $\begin{array}{l}0.9618 \\
\left(43.9^{\circ}\right) \\
\end{array}$ & $\begin{array}{l}1.0152 \\
\left(45.4^{\circ}\right)\end{array}$ & $\begin{array}{l}1.014 \\
\left(45.4^{\circ}\right)\end{array}$ & $\begin{array}{l}1.0073 \\
\left(45.2^{\circ}\right) \\
\end{array}$ & $\begin{array}{l}1.0065 \\
\left(45.2^{\circ}\right) \\
\end{array}$ & $\begin{array}{l}1.0428 \\
\left(46.2^{\circ}\right) \\
\end{array}$ \\
\hline$r$ & -0.05071 & 0.5116 & 0.7594 & 0.8645 & 0.7846 & 0.7941 & 0.7672 \\
\hline
\end{tabular}

Table 3: Approach II

\begin{tabular}{|l|l|l|l|c|l|l|l|}
\hline \multirow{2}{*}{$\begin{array}{l}\text { Type of } \\
\text { error }\end{array}$} & \multicolumn{6}{l}{ Type of membership functions } \\
\cline { 2 - 8 } & TRI & GBELL & DSIG & GAUSS & PI & PSIG & TRAP \\
\hline MSE & 0.120 & $\mathbf{0 . 0 7 8}$ & 0.2054 & 0.1357 & 0.2244 & 0.2054 & 0.2200 \\
\hline HMSE & 0.060 & $\mathbf{0 . 0 3 9}$ & 0.1027 & 0.0678 & 0.1122 & 0.1027 & 0.1100 \\
\hline RMSE & 0.347 & $\mathbf{0 . 2 7 9}$ & 0.4532 & 0.3684 & 0.4737 & 0.4532 & 0.4691 \\
\hline ARB & 0.068 & $\mathbf{0 . 0 6 1 4}$ & 0.0994 & 0.0838 & 0.0955 & 0.0994 & 0.0992 \\
\hline
\end{tabular}

Table 4: $\mathrm{m}$ and $\mathrm{r}$ values using approach II

\begin{tabular}{|c|l|l|l|l|l|l|l|}
\hline \multirow{2}{*}{$\begin{array}{l}\text { Slope and } \\
\text { correlation } \\
\text { coefficient }\end{array}$} & \multicolumn{6}{|l|}{ Type of membership functions } \\
\cline { 2 - 8 } & TRI & GBELL & DSIG & GAUSS & PI & PSIG & TRAP \\
\hline$m$ & 0.9967 & 1.0209 & 1.0158 & $\mathbf{1 . 0 1 5}$ & 1.0227 & 1.0158 & 1.0228 \\
& $\left(44.9^{\circ}\right)$ & $\left(45.6^{\circ}\right)$ & $\left(45.4^{\circ}\right)$ & $\left.\mathbf{( 4 5 . 4}^{\circ}\right)$ & $\left(45.6^{\circ}\right)$ & $\left(45.4^{\circ}\right)$ & $\left(45.6^{\circ}\right)$ \\
\hline$r$ & 0.9069 & $\mathbf{0 . 9 4 8 3}$ & 0.7586 & 0.8675 & 0.7447 & 0.7587 & 0.7485 \\
\hline
\end{tabular}

Table 5: Approach III

\begin{tabular}{|l|l|l|l|l|l|l|l|}
\hline \multirow{2}{*}{$\begin{array}{l}\text { Type of } \\
\text { error }\end{array}$} & \multicolumn{7}{|c|}{ Type of membership functions } \\
\cline { 2 - 8 } & TRI & GBEL & DSIG & GAUSS & PI & PSIG & TRAP \\
\hline MSE & 0.414 & 0.746 & 0.3231 & 0.2320 & 0.5183 & $\mathbf{0 . 0 2 8 4}$ & 0.4545 \\
\hline HMSE & 0.207 & 0.373 & 0.1615 & 0.1160 & 0.2591 & $\mathbf{0 . 0 1 4 2}$ & 0.2272 \\
\hline RMSE & 0.643 & 0.864 & 0.5684 & 0.4817 & 0.7199 & $\mathbf{0 . 1 6 8 5}$ & 0.6741 \\
\hline ARB & 0.118 & 0.137 & 0.0969 & 0.0900 & 0.1301 & $\mathbf{0 . 0 3 8 7}$ & 0.1268 \\
\hline
\end{tabular}

Table 6: $\mathrm{m}$ and $\mathrm{r}$ values using approach III

\begin{tabular}{|c|l|l|l|l|l|l|l|}
\hline $\begin{array}{l}\text { Slope and } \\
\text { correlation } \\
\text { coefficient }\end{array}$ & TRI & GBELL & DSIG & GAUSS & PI & PSIG & TRAP \\
\hline$m$ & 1.0366 & 0.9838 & 0.9551 & $\mathbf{1 . 0 1 1 5}$ & 1.0383 & 1.0293 & 1.0345 \\
& $\left(46.0^{\circ}\right)$ & $\left(44.5^{\circ}\right)$ & $\left(43.7^{\circ}\right)$ & $\left.\mathbf{( 4 5 . 3}^{\circ}\right)$ & $\left(46.1^{\circ}\right)$ & $\left(45.8^{\circ}\right)$ & $\left(46.0^{\circ}\right)$ \\
\hline$r$ & 0.5897 & 0.2157 & 0.5599 & 0.7128 & 0.5173 & $\mathbf{0 . 9 9 6 3}$ & 0.5455 \\
\hline
\end{tabular}


Table 7: Approach IV

\begin{tabular}{|l|l|l|l|l|c|c|c|}
\hline \multirow{2}{*}{$\begin{array}{l}\text { Type of } \\
\text { error }\end{array}$} & \multicolumn{6}{|c|}{ Type of membership functions } \\
\cline { 2 - 8 } & TRI & GBELL & DSIG & GAUSS & PI & PSIG & TRAP \\
\hline MSE & 0.254 & 0.164 & 0.2021 & $\mathbf{0 . 1 5 2 2}$ & 0.2713 & 0.1671 & 0.2535 \\
\hline HMSE & 0.127 & 0.082 & 0.1010 & $\mathbf{0 . 0 7 6 1}$ & 0.1356 & 0.0835 & 0.1267 \\
\hline RMSE & 0.504 & 0.405 & 0.4495 & $\mathbf{0 . 3 9 0 1}$ & 0.5209 & 0.4087 & 0.5035 \\
\hline ARB & 0.089 & 0.079 & 0.0815 & $\mathbf{0 . 0 7 3 1}$ & 0.0983 & 0.0803 & 0.0904 \\
\hline
\end{tabular}

inherent problem of getting struck in the local minima. The measure of error for all the membership functions are good as the errors are less than 0.1. the least error is obtained for 'gbell' membership functions although the measure of errors is close to each other for the different membership functions. Table 4 provides the slope and the correlation coefficient of the different membership functions. As seen in Table 4, the correlation coefficient is 0.94838 , which suggests good agreement between the predicted and experimental value.

Table 5 shows the different measures of error for approach 3. As seen from Table 3, the error values of MSE, HMSE, RMSE, and ARB is least for 'psig' membership function. The 'psig' membership functions are the product of two sigmoid functions. Also, the $r$ values of 'psig' membership function is 0.99634 , which is very near to 1 and suggests a strong correlation between the predicted and the experimental value. In this approach the input spaces are divided into clusters and thus the computational time is increased if small radius of clusters is considered. Also, back propagation algorithm is used for updating the weights of the network. Although back propagation does not deliver global optimum points but good correlation coefficient between the predicted and the target values are obtained.
The error performance from approach IV is shown in Table 7. The 'gauss' type of membership function used in approach IV yields minimum error. In this approach hybrid technique is for optimization of the network parameters. It is seen that all the membership functions have responded well as the error performance for all the membership functions is less than 0.1. Among all the membership functions it is inferred that the 'gauss' type of membership provides the least measure of error. The claims could also be supported from Table 8, where the ' $m$ ' value is 1.0032. The slope of the best fit line for 'gauss' type of membership function is $45.1^{\circ}$, which yields the ideal is $45^{\circ}$. The $r$ values for each of the membership function is not close to unity but for 'gauss' type of membership function highest value is obtained among all the membership functions. Thus, the 'gauss' type of membership function is the best function for approach IV. Fastest convergence is achieved using this approach.

For manufacturing analytics problem, improvement of accuracy is the main objective. For manufacturing, curvilinear membership functions are found to yield better results compared to 'tri' and 'trap' membership functions. From the above discussion, it is understood that the membership functions varied with the change in the type of the

Table 8: $\mathrm{m}$ and $\mathrm{p}$ values using approach IV

\begin{tabular}{|c|c|l|l|l|l|l|l|}
\hline \multirow{2}{*}{$\begin{array}{l}\text { Slope and } \\
\begin{array}{c}\text { correlation } \\
\text { coefficient }\end{array}\end{array}$} & \multicolumn{2}{|c|}{ Types of membership functions } \\
\cline { 2 - 8 } & TRI & GBELL & DSIG & GAUSS & PI & PSIG & TRAP \\
\hline$m$ & 1.0013 & 1.0012 & 0.9965 & $\mathbf{1 . 0 0 3 2}$ & 0.9932 & 1.0053 & 0.9847 \\
& $\left(45.0^{\circ}\right)$ & $\left(45.0^{\circ}\right)$ & $\left(44.9^{\circ}\right)$ & $\left.\mathbf{( 4 5 . 1}^{\circ}\right)$ & $\left(44.8^{\circ}\right)$ & $\left(45.2^{\circ}\right)$ & $\left(44.6^{\circ}\right)$ \\
\hline$r$ & 0.6679 & 0.8274 & 0.7568 & $\mathbf{0 . 8 4 8 2}$ & 0.6388 & 0.8291 & 0.6628 \\
\hline
\end{tabular}

Table 9: Analysis of variance of different types of network using ( $r$ )

\begin{tabular}{|c|c|c|c|c|c|}
\hline Source & DF & Adj. SS & Adj. MS & F-Value & P-Value \\
\hline Type of network & 3 & 0.2292 & 0.0764 & 1.76 & 0.181 \\
\hline Error & 24 & 1.0404 & 0.0433 & & \\
\hline Total & 27 & 1.2696 & & & \\
\hline
\end{tabular}


technique used for ANFIS. From the discussion it is unclear which type of technique combined with the type of membership function would yield the best results for prediction of the mean thickness. For analysing an ANOVA analysis is presented in Table 9. Table 9 shows the variance of different types of the network used in this study using the $(r)$ values. The ANOVA analysis is carried for 95 percent confidence level. The $p$-value as seen in Table 9 is 0.181 which is greater than 0.05 . The $p$-value suggests that the type of network have an insignificant effect on the prediction of the mean thickness of flow formed tubes. Also, it suggests that the networks have the same efficiency in the prediction of the mean thickness.

\section{Conclusion}

Backward metal flow forming process is a complex incremental forming process. Although it requires simple tooling for manufacturing of the tubes but understanding the deformation under the roller preform contact zone is difficult. There is very limited research on the relationship between the input and the output parameters such as the mean thickness of flow formed tubes. Thus, predicting the mean thickness for a set of input parameters is a difficult. This research aims to solve the problem with development of a soft computing model. With this model, easy and quick determination of the final dimension of flow formed tubes could be made for the input parameters. This technique would be very useful in the industries for controlling the quality of flow formed tubes. In this research, four different strategies of ANFIS technique is used along with seven different membership function. The techniques are used for prediction of mean thickness of the flow formed tubes. For the different techniques along with the membership functions the different measures of error performance are evaluated for the testing data. Based on this, the following conclusion could be drawn:

- ANFIS is a powerful soft computing tool that could be used for determination of the final dimension of formed tubes by the complex incremental backward metal flow forming process.

- For manufacturing analytics where the accuracy of the formed component is the controllable feature. From the analysis it is stated that the curvilinear membership functions are highly acceptable for modelling of this forming process. The 'psig' membership function for approach III yielded the least error and highest correlation coefficient. The 'gbell' membership function yields the least error for approach II.
The 'gauss' membership function yield the least error for approach I and IV respectively.

- Fast convergence is achieved by subtractive clustering with hybrid optimization technique in comparison to the other three approaches.

- The correlation coefficient $r$ is close to unity for the 'psig' membership function for approach III. The second best is for 'gbell' membership function that have a value of 0.9483 .

- Smooth curvilinear generates better results as compared to linear curve membership functions used in this research.

- For lower input parameters grid partition should be used rather than the subtractive clustering technique.

- An ANOVA analysis is performed to analyse significant contribution of each technique. The $p$-value obtained for the research implies that all four approaches have the same efficiency in predicting the mean thickness. Thus, any of one of the approach could be used for developing a predictive model of flow forming process.

\section{References and Notes}

[1] D. Marini, D. Cunningham, P. Xirouchakis and J. R. Corney, "Flow Forming: A Review of Research Methodologies, Prediction Models And Their Applications," International Journal of Mechanical Engineering and Technology, vol. 7, no. 5, pp. 285-315, 2016

[2] "The FABRICATOR.com," [Online]. Available: https://www. thefabricator.com/thefabricator/article/stamping/metalspinning-versus-flow-forming. [Accessed 20 August 2020].

[3] "pmfind.com," [Online]. Available: https://www.pmfind.com/ benefits/flowforming-process-benefits-process. [Accessed 20 September 2020].

[4] "https://www.parasdefence.com/," [Online]. Available: https:// www.parasdefence.com/productssolutions/heavyengineering/flow-formed-tubes/. [Accessed 20 October 2020].

[5] D. Marini, D. Cunningham and J. Corney, "A Review of Flow Forming Processes and Mechanisms," Engineering Materials, Vols. 651-653, pp. 750-758, 2015.

[6] C. Wong, T. Dean and J. Lin, "A review of spinning, shear forming and flow forming processes," International Journal of Machine Tools and Manufacture, no. 43, pp. 1419-1435, 2003.

[7] B. Podder, P. Banerjee, K. R. Kumar and N. Hui, "Flow forming of thin-walled precision shells," Sadhana, vol. 43, pp. 1-16, 2018.

[8] M. Hayama and H. Kudo, "Analysis of diametral growth and working forces in tube spinning," Bulletin of JSME, vol. 22, pp. 776-784, 1979.

[9] H. Nagarajan, H. Kotrappa, C. Mallanna and V. Venkatesh, "Mechanics of Flow Forming," Journal of Manufacturing Technology, no. 30, pp. 159-162, 1981. 
[10] M. J. Davidson, K. Balasubramanian and G. T. R. N. "Experimental investigation on flow-forming of AA6061 alloy-A Taguchi approach," Journal of Materials Processing Technology, vol. 200, p. 283-287, 2008.

[11] L.Wang and H. Long, "Roller path design by tool compensation in multi-pass conventional spinning," Materials and Design, no. 46, pp. 645-653, 2013.

[12] P. Banerjee, N. B. Hui, M. K. Dikshit, R. Laha and S. Das, "Modelling and optimization of mean thickness of backward for formed tubes using regression analysis, particle swarm optimization and neural network," SN Applied Sciences, 2020.

[13] B. Podder, P. Banerjee, K. R. Kumar and N. B. Hui, "Development of ANFIS Model for Flow Forming of Solution Annealed H3O Aluminium Tubes," Solid State Phenomena, vol. 261, pp. 378-385, 2017.

[14] B. Podder, P. Banerjee, K. R. Kumar and N. Hui, "Forward and reverse modelling of flow forming of solution annealed $\mathrm{H} 30$ aluminium tubes," Neural Computing and Applications, vol. 32, p. 2081-2093, 2018.

[15] J. S. Jang and C. T. Sun, "Neuro-fuzzy modeling and control," Proceedings of the IEEE, vol. 83, no. 3, pp. 378-406, 1995.

[16] D. K. Pratihar, Soft Computing, New Delhi: Narosa, 2018.

[17] C. C. Wong, T. A. Dean and J. Lin, "A review of spinning, shear forming and flow forming processes," International Journal of Machine Tools and Manufacture, vol. 43, pp. 1419-1435, 2003.

[18] C. Wong, J. Lin and T. Dean, "Effects of roller path and geometry on the flow forming of solid cylindrical components," Journal of Materials Processing Technology, no. 167, pp. 344-353, 2005.

[19] B. Podder, P. Banerjee, K. R. Kumar and N. B. Hui "Study of the influences of process parameters on cold flow forming of Al-tubes," International Journal of Modern Manufacturing Technologies, vol. 11, p. 106, 2019.

[20] D. Marini, D. Cunningham and J. Corney, "A review of flow forming processes and mechanisms," Journal of Key Engineering Materials, pp. 750-758, 2015.

[21] C. Wong, T. Dean and J. Lin, "Incremental forming of solid cylindrical components using flow forming principles," Journal of Materials Processing Technology, no. 153-154, pp. 60-66, 2004.

[22] M. Mohebbi and A. Akbarzadeh, "Experimental study and FEM analysis of redundant strains in flow forming of tubes," Journal of Material Processing Technology, vol. 2, no. 210, pp. 389-395, 2010.

[23] M. H. Parsa, A. M. A. Pazooki and M. N. Ahmadabadi, "Flowforming and flow formability simulation," International Journal of Advanced Manufacturing Technology, vol. 42, p. 463-473, 2009
[24] K. M. Rajan, P. U. Deshpande and K. Narasimhan, "Experimental studies on bursting pressure of thin-walled flow formed pressure vessels," Journal of Materials Processing Technology, no. 125, pp. 228-234, 2002. 
Annexure

Table 1:Training data

\begin{tabular}{|c|c|c|c|c|c|}
\hline $\begin{array}{l}\text { EXP. } \\
\text { NO }\end{array}$ & $\begin{array}{c}\text { PRFORM } \\
\text { IDENTIFICATION }\end{array}$ & $\begin{array}{c}\text { FEED-SPEED } \\
\text { RATIO } \\
(\mathrm{mm} / \mathrm{rev})\end{array}$ & $\begin{array}{l}\text { INFEED } \\
(\mathrm{mm})\end{array}$ & $\begin{array}{c}\text { AXIAL } \\
\text { STAGGER } \\
(\mathrm{mm})\end{array}$ & $\begin{array}{c}\text { Mean } \\
\text { THICKNESS } \\
(\mathrm{mm})\end{array}$ \\
\hline 1 & 1H30010530095 & 0.5 & 3 & 9.5 & 4.5075 \\
\hline 2 & 1H30020630095 & 0.6 & 3 & 9.5 & 4.6375 \\
\hline 3 & $1 \mathrm{H} 30030730095$ & 0.7 & 3 & 9.5 & 4.6325 \\
\hline 4 & $1 \mathrm{H} 30040830095$ & 0.8 & 3 & 9.5 & 4.6125 \\
\hline 5 & $1 \mathrm{H} 30050535095$ & 0.5 & 3.5 & 9.5 & 3.97 \\
\hline 6 & 1H30060635095 & 0.6 & 3.5 & 9.5 & 4.0675 \\
\hline 7 & $1 \mathrm{H} 30070735095$ & 0.7 & 3.5 & 9.5 & 4.1125 \\
\hline 8 & 1H30080835095 & 0.8 & 3.5 & 9.5 & 4.1725 \\
\hline 9 & 1H30090540095 & 0.5 & 4 & 9.5 & 3.555 \\
\hline 10 & 1H30100640095 & 0.6 & 4 & 9.5 & 3.5975 \\
\hline 11 & 1H30110740095 & 0.7 & 4 & 9.5 & 3.665 \\
\hline 12 & 1H30120840095 & 0.8 & 4 & 9.5 & 3.5975 \\
\hline 13 & 1H30130545095 & 0.5 & 4.5 & 9.5 & 3.115 \\
\hline 14 & 1H30140645095 & 0.6 & 4.5 & 9.5 & 3.105 \\
\hline 15 & 1H30150745095 & 0.7 & 4.5 & 9.5 & 3.1525 \\
\hline 16 & 1H30160845095 & 0.8 & 4.5 & 9.5 & 3.2725 \\
\hline 17 & 1H30170530110 & 0.5 & 3 & 11 & 4.64 \\
\hline 18 & 1H30180630110 & 0.6 & 3 & 11 & 4.5625 \\
\hline 19 & $1 \mathrm{H} 30190730110$ & 0.7 & 3 & 11 & 4.5925 \\
\hline 20 & 1H30200830110 & 0.8 & 3 & 11 & 4.685 \\
\hline 21 & $1 \mathrm{H} 30210535110$ & 0.5 & 3.5 & 11 & 4.085 \\
\hline 22 & 1H30220635110 & 0.6 & 3.5 & 11 & 4.0825 \\
\hline 23 & $1 \mathrm{H} 30230735110$ & 0.7 & 3.5 & 11 & 4.155 \\
\hline 24 & 1H30240835110 & 0.8 & 3.5 & 11 & 4.1775 \\
\hline 25 & $1 \mathrm{H} 30250540110$ & 0.5 & 4 & 11 & 3.6475 \\
\hline 26 & 1H30260640110 & 0.6 & 4 & 11 & 3.71 \\
\hline 27 & 1H30270740110 & 0.7 & 4 & 11 & 3.6625 \\
\hline 28 & 1H30280840110 & 0.8 & 4 & 11 & 3.71 \\
\hline 29 & 1H30290545110 & 0.5 & 4.5 & 11 & 3.16 \\
\hline 30 & $1 \mathrm{H} 30300645110$ & 0.6 & 4.5 & 11 & 3.155 \\
\hline 31 & $1 \mathrm{H} 30310745110$ & 0.7 & 4.5 & 11 & 3.2075 \\
\hline 32 & 1H30320845110 & 0.8 & 4.5 & 11 & 3.275 \\
\hline 33 & 1H30330530125 & 0.5 & 3 & 12.5 & 4.5875 \\
\hline 34 & 1H30340630125 & 0.6 & 3 & 12.5 & 4.5575 \\
\hline 35 & 1H30350730125 & 0.7 & 3 & 12.5 & 4.67 \\
\hline 36 & 1H30360830125 & 0.8 & 3 & 12.5 & 4.655 \\
\hline 37 & 1H30370535125 & 0.5 & 3.5 & 12.5 & 4.1225 \\
\hline 38 & 1H30380635125 & 0.6 & 3.5 & 12.5 & 4.0975 \\
\hline 39 & 1H30390735125 & 0.7 & 3.5 & 12.5 & 4.1925 \\
\hline 40 & 1H30400835125 & 0.8 & 3.5 & 12.5 & 4.1725 \\
\hline 41 & 1H30410540125 & 0.5 & 4 & 12.5 & 3.63 \\
\hline 42 & 1H30420640125 & 0.6 & 4 & 12.5 & 3.61 \\
\hline 43 & 1H30430740125 & 0.7 & 4 & 12.5 & 3.74 \\
\hline 44 & 1H30440840125 & 0.8 & 4 & 12.5 & 3.7825 \\
\hline 45 & 1H30450545125 & 0.5 & 4.5 & 12.5 & 3.18 \\
\hline 46 & 1H30460645125 & 0.6 & 4.5 & 12.5 & 3.2175 \\
\hline 47 & $1 \mathrm{H} 30470745125$ & 0.7 & 4.5 & 12.5 & 3.215 \\
\hline 48 & 1H30480845125 & 0.8 & 4.5 & 12.5 & 3.3225 \\
\hline 49 & $1 \mathrm{H} 30490530140$ & 0.5 & 3 & 14 & 4.5525 \\
\hline 50 & 1H30500630140 & 0.6 & 3 & 14 & 4.64 \\
\hline 51 & 1H30510730140 & 0.7 & 3 & 14 & 4.66 \\
\hline 52 & 1H30520830140 & 0.8 & 3 & 14 & 4.535 \\
\hline 53 & 1H30530535140 & 0.5 & 3.5 & 14 & 4.075 \\
\hline 54 & 1H30540635140 & 0.6 & 3.5 & 14 & 4.0375 \\
\hline 55 & 1H30550735140 & 0.7 & 3.5 & 14 & 4.155 \\
\hline 56 & 1H30560835140 & 0.8 & 3.5 & 14 & 4.185 \\
\hline 57 & $1 \mathrm{H} 30570540140$ & 0.5 & 4 & 14 & 3.6225 \\
\hline 58 & 1H30580640140 & 0.6 & 4 & 14 & 4.6375 \\
\hline 59 & 1H30590740140 & 0.7 & 4 & 14 & 3.7375 \\
\hline 60 & 1H30600840140 & 0.8 & 4 & 14 & 3.7325 \\
\hline 61 & 1H30610545140 & 0.5 & 4.5 & 14 & 3.17 \\
\hline 62 & 1H30620645140 & 0.6 & 4.5 & 14 & 3.21 \\
\hline 63 & 1H30630745140 & 0.7 & 4.5 & 14 & 3.2475 \\
\hline 64 & 1H30640845140 & 0.8 & 4.5 & 14 & 3.31 \\
\hline
\end{tabular}


Acta Mechanica Slovaca

Journal published by Faculty of Mechanical Engineering - Technical University of Košice

Table 2. Test case data

\begin{tabular}{|c|l|l|l|l|}
\hline $\begin{array}{c}\text { Data } \\
\text { Set No. }\end{array}$ & $\begin{array}{c}\text { Feed speed } \\
\text { ratio }\end{array}$ & Infeed & $\begin{array}{c}\text { Axial } \\
\text { stagger }\end{array}$ & $\begin{array}{c}\text { Mean Thickness } \\
\text { (Experimental) }\end{array}$ \\
\hline 1. & 0.55 & 3.7 & 12 & 3.459 \\
\hline 2. & 0.75 & 4.2 & 12 & 3.394 \\
\hline 3. & 0.65 & 3.2 & 10 & 4.36 \\
\hline 4. & 0.72 & 3.4 & 10 & 4.138 \\
\hline 5. & 0.65 & 3.2 & 12 & 4.368 \\
\hline 6. & 0.4 & 2.8 & 9 & 4.56 \\
\hline 7. & 0.9 & 2.5 & 9 & 5.088 \\
\hline 8. & 0.45 & 4.8 & 15 & 2.825 \\
\hline
\end{tabular}

